\title{
Relationship between meaning in life and death anxiety in the elderly: self-esteem as a mediator
}

\author{
Jiaxi Zhang ${ }^{1}$, Jiaxi Peng ${ }^{2^{*}}$ (D), Pan Gao ${ }^{1}$, He Huang ${ }^{3}$, Yunfei $\mathrm{Cao}^{2}$, Lulu Zheng $^{2}$ and Danmin Miao ${ }^{3^{*}}$
}

\begin{abstract}
Background: Death anxiety is a common phenomenon in all societies. Older adults may be more prone to death anxiety than their younger counterparts; however, death anxiety among older adults is not well understood. This study explores the relationship between meaning in life, self-esteem, and death anxiety in senior citizens in China.

Methods: A total of 283 older adults participated in this study; data were collected via the Meaning in Life Questionnaire, the Rosenberg Self-Esteem Scale, and the Death Anxiety Scale.

Results: Results show that the dimensions of meaning in life, presence of meaning ( $r=-0.43, p<0.01)$, search for meaning $(r=-0.31, p<0.01)$, and self-esteem $(r=-0.54, p<0.01)$ were each negatively correlated with death anxiety. Regression analysis reveals that meaning in life significantly predicted self-esteem and death anxiety $\left(F=45.70, p<0.01 ; R^{2}=0.33\right.$ ). Path analysis indicated that self-esteem either completely or partially mediated the effects of meaning in life on death anxiety in older adults.
\end{abstract}

Conclusions: Overall, meaning in life appears to be significantly correlated with death anxiety in older adults, and self-esteem can mediate this effect.

Keywords: Meaning in life, Death anxiety, Self-esteem, Mental health, Older adults

\section{Background}

Older adults and the aging population must face the prospect of death [1]. Death is an inevitable aspect of life; as older adults approach it, they can easily experience anxiety, a reduced sense of safety, and even strong fear $[2,3]$. In the psychology field, this mental state is termed death anxiety. Death anxiety is a conscious or unconscious psychological state resulting from a defense mechanism that can be triggered when people feel threatened by death [4]. The North American Nursing Diagnosis Association defines death anxiety as a feeling of unsafety, anxiety, or fear related to death or neardeath [5]. Death anxiety is a common phenomenon in all societies, although older adults may be more prone to anxiety and fear when encountering death-related events compared to their younger counterparts [6]. Thus,

\footnotetext{
* Correspondence: pengjx880124@hotmail.com; psych@fmmu.edu.cn

${ }^{2}$ College of Teachers, Chengdu University, Chengdu, China

${ }^{3}$ Department of Military Medical Psychology, Air Force Military Medical

University, Xi'an, China

Full list of author information is available at the end of the article
}

relieving death anxiety in older adults may play an important role in improving their mental health and quality of life.

Several theoretical models relevant to the study of death anxiety in older adults have appeared in the literature [7-9]. Examples include self-realization theories, personal construct theory, self-concept discrepancy theory, search-for-meaning theories, theories of denial, and others. Four aspects tend to be common across these models: death is conceptualized as a radical transformation and separation, annihilation of the self, a threat to the realization of life's basic goals and propensities, and a threat to the meaningfulness of life [10]. Such diversity in theoretical approaches has led to various perspectives on death anxiety; however, these theories are accompanied by drawbacks. One weakness relates to the substantial amount of overlap among theories [10]. Florian and Mikulincer pointed out that threats to death anxiety can be replaced by two categories depending on the chosen theory: either the meaningfulness of life or self-realization 
[11]. More specifically, threats to death anxiety can be classified based on two factors: external causes, such as presence and search for meaning in life; and the internalization or overall evaluation of the self. Thus, to explore more efficiently the underlying psychological mechanisms of death anxiety in older adults, external causes (meaning in life) and the internalization process (self-esteem) are included in this study. The purpose of this research is to explore the relationships among death anxiety, meaning in life, and self-esteem with a focus on the mediating effect of self-esteem between meaning in life and death anxiety in Chinese older adults.

One variable related to death anxiety is meaning in life. Frazier proposed and defined meaning in life as the act of humans cognizing and pursuing life goals and targets $[12,13]$; that is, each person possesses unique goals or targets in life and must clearly understand what to do to achieve said targets-and make an effort to do it [14]. Steger and Frazier defined meaning in life as an individual's ability to understand life, such as understanding oneself and the outside world and adapting to it [12]. Steger conceptualized meaning in life from multiple dimensions but ultimately considered it an individual's understanding of life and the pursuit of his/her life goals and missions. Steger then proposed a two-dimensional model of meaning in life: presence of and search for meaning [15]. Presence of meaning, the cognitive dimension, is defined as the degree of devotion toward one's goals, targets, or missions in life; this dimension focuses on the outcome. Search for meaning, the motivational dimension, emphasizes the process by which individuals actively identify meaning and targets in life. When individuals achieve these targets, they experience meaning in life. Many measurement scales assessing meaning in life, such as the Purpose in Life Test [16] and Sense of Coherence Scale [17], have conceptualized it as a single construct; it is therefore nearly impossible to ascertain particular aspects of life meaning that may be associated with certain outcomes. Even so, most researchers have thus far supported this two-dimensional model [18].

The relationship between meaning in life and death anxiety has been studied extensively. Routledge and Juhl asked participants to imagine the scenes of their death and discovered that only those with weaker meaning in life experienced death anxiety [19]. A stronger feeling of meaning in life has been shown to correlate with a lesser degree of death anxiety $[1,19]$. Tang et al. found meaning in life to be significantly and negatively correlated with death anxiety in Chinese college students: individuals who perceived greater meaning in life could accept death and hence experienced less death anxiety [20]. Lyke indicated that meaning in life can significantly and negatively predict fear of death among young people [21]. According to meaning management theory (MMT), first proposed by Wong, human beings are meaningseeking and meaning-making creatures with two primary motivations: to survive and to find a meaning and reason for survival [22]. MMT predicts that the pursuit of meaning in life is the best way to alleviate death anxiety. MMT also assumes that people wish to live a meaningful life and that focusing on positive growth tendencies is preferable to establishing defense mechanisms against death anxiety. Put simply, if individuals believe their existence is meaningful and that they play important roles in their community, then they may not feel threatened by inevitable death [23, 24]. As discussed above, a strong theoretical link has been established between meaning in life and death anxiety.

Another psychological construct closely related to death anxiety is self-esteem, a primary factor in death anxiety management. The literature is replete with evidence that self-esteem serves as a buffer against death anxiety. Researchers using self-report and physiological indices have found that self-esteem protects individuals from death anxiety. People with low levels of self-esteem tend to experience anxiety in response to death, whereas threats to selfesteem induce death anxiety and defense of selfesteem reduces death anxiety [25-27]. Rosenblatt and colleagues reported that, when individuals were exposed to videotaped scenes of death, viewers with high self-esteem reported less anxiety or fear [28]. Other studies have indicated that death anxiety is related to low selfesteem $[2,29]$. Terror management theory (TMT), which is based on work by Becker, posits that humans possess a dual-process system that serves a protective function against human awareness of vulnerability and eventual mortality [30]. TMT further predicts that people who adhere to cultural values are better shielded than others against the potential for anxiety. This model also suggests that individuals with high self-esteem will exhibit less anxiety toward death-related scenes.

Although many studies and theoretical models have indicated that meaning in life can alleviate death anxiety, with self-esteem as an important buffer against such anxiety, the trilateral relations among death anxiety, meaning in life, and self-esteem warrant further investigation. Existing theories, such as TMT, provide indirect evidence for this mediating effect. TMT argues that people's awareness of the inevitability of death can produce anxiety. Individuals have therefore generated numerous defense mechanisms to minimize death-related anxiety. One mechanism involves conforming to the value standards endorsed by one's cultural worldview, which affords people a sense of meaning in life that functions as a buffer against potential anxiety related to mortality salience. People are also capable of raising their self-esteem by enhancing their sense of meaning and purpose in life, which constitutes another defense mechanism against death 
anxiety according to TMT [31]. In short, TMT can contextualize the effects of meaning in life on death anxiety through the mediating role of self-esteem [24]. In line with TMT, the current study aims to verify the mediating role of self-esteem in the relationship between meaning in life and death anxiety based on the following hypothesis: meaning in life can influence self-esteem and reduce death anxiety through its mediating effect on self-esteem.

\section{Methods}

\section{Participants and procedures}

Participants comprised a convenience sample of 294 older adults (124 men, 42.1\%; 170 women, $57.9 \%$ ) recruited from four large communities. Data were collected in community centers. Participants ranged from 65 to 73 years $\left(M_{\text {age }}=67.16\right.$ years; $\left.S D=1.82\right)$. All participants were married and retired. Nearly all participants (271; 92.3\%) reported living with their spouses, children, or other relatives; 23 (7.7\%) reported living alone. All participants completed questionnaires in their respective communities. Illiterate participants, who had fewer than 3 years of education and were unable to read or write (13 older adults, 4.4\%), completed the questionnaires with help from the researcher. Among the 294 questionnaires that were distributed and collected, 283 were valid. Eleven questionnaires were incomplete and excluded from analysis (questionnaires were printed two-sided, but some participants failed to complete all items on both sides). Participants received a carton of eggs as compensation. This study was approved by the Committee on Human Experimentation at the authors' university.

\section{Instruments}

\section{Meaning in life}

The 10-item Meaning in Life Questionnaire was used to assess the degree to which participants felt their life was meaningful [32]. The Meaning in Life Questionnaire consists of two subscales: search for meaning in life and presence of meaning in life. Example items for the two subscales are "I am seeking a purpose or mission for my life (search)" and "I have a good sense of what makes my life meaningful (presence)." Item responses ranged from $1=$ strongly disagree to $7=$ strongly agree. Research has supported the reliability and validity of this scale [33, 34]. For the purpose of this study, the Meaning in Life Questionnaire was translated into Chinese and back-translated from Chinese to English to ensure accurate translation; the translation was found to have good reliability and validity [35]. In the current study, estimated internal consistencies were $\alpha=0.74$ (search) and $\alpha=0.81$ (presence).

\section{Self-esteem}

The Rosenberg Self-Esteem Scale, a measure of individual self-esteem, consists of 10 self-esteem-related items such as "On the whole I am satisfied with myself" and "All in all, I am inclined to feel that I am a failure." Each item is rated on a 7-point Likert scale, ranging from $1=$ strongly disagree to $7=$ strongly agree [36]. The total self-esteem score is the sum of items with reverse scoring of relevant items. The Rosenberg Self-Esteem Scale was translated into Chinese by Cheung and Lau and found to have good reliability and validity [36]. To ensure translation accuracy, the scale was back-translated from Chinese to English. The estimated internal consistency was $\alpha=$ 0.82 in this study.

\section{Death anxiety}

Templer's unidimensional Death Anxiety Scale consists of 15 items. Six items are reverse scored, such that higher scores indicate greater death anxiety. Sample items include "I am very much afraid to die" and "I seldom think of death." In a prior study, this scale was reported to have a test-retest reliability of 0.83 and reasonable internal consistency [37]. The Templer Death Anxiety Scale was translated into Chinese and back-translated from Chinese to English to ensure accurate translation [20]; the translated measure demonstrated good reliability and validity with an estimated internal consistency of $\alpha=0.71$ in this study.

\section{Data analysis}

Pearson correlation coefficients and hierarchical regression analyses were used to identify relationships among meaning in life, self-esteem, and death anxiety. Baron and Kenny's recommendations were followed in testing whether self-esteem mediated the link between meaning in life and death anxiety based on hierarchical regression analyses [38]. The following process was used: first, a simple regression analysis was performed with independent variables (presence of meaning and search for meaning) predicting the dependent variable (death anxiety) to test the significance of c; second, a simple regression analysis was conducted with independent variables (presence of meaning and search for meaning) predicting the mediating variable (self-esteem) to test the significance of a; third, a simple regression analysis was carried out with the mediating variable (self-esteem) predicting the dependent variable (death anxiety) to test the significance of $b$; and fourth, a multiple regression analysis was conducted with the independent variables and mediating variable predicting the dependent variable. Then, path analysis was used to test the mediation effect in Amos 17.0. Finally, the bootstrap method was adopted to test the significance of indirect and direct effects in the mediating model [39].

\section{Results}

Table 1 lists the means, descriptive statistics, and intercorrelations of all variables. Presence of meaning was positively correlated with search for meaning $(r=0.50$, 
Table 1 Descriptive statistics and inter-correlations of all variables

\begin{tabular}{lllllll}
\hline & 1 & 2 & 3 & 4 & Mean & SD \\
\hline 1. Presence of meaning & 1 & & & 25.25 & 6.56 \\
2. Search for meaning & $0.50^{* *}$ & 1 & & 24.22 & 5.62 \\
3. Self-esteem & $0.52^{* *}$ & $0.36^{* *}$ & 1 & & 29.79 & 5.13 \\
4. Death anxiety & $-0.43^{* *}$ & $-0.31^{* *}$ & $-0.54^{* *}$ & 1 & 12.65 & 5.15 \\
\hline Note: ${ }^{* *} p<0.01$ & & & & & &
\end{tabular}

$p<0.01)$ and self-esteem $(r=0.52, p<0.01)$ and negatively correlated with death anxiety $(r=-0.43, p<0.01)$. Similarly, search for meaning was associated with selfesteem $(r=0.36, p<0.01)$ and death anxiety $(r=-0.31$, $p<0.01)$. Self-esteem was negatively correlated with death anxiety $(r=-0.54, p<0.01)$.

Following the steps of the mediation procedure, a series of simple regression analyses (see Table 2 ) indicated that presence of meaning $(\beta=-0.37, p<0.01)$ and search for meaning $(\beta=-0.13, p<0.05)$ were each negatively associated with death anxiety (Model 1 ); presence of meaning $(\beta=0.36, p<0.01)$ and search for meaning $(\beta=0.12, p<$ $0.05)$ were each positively correlated with self-esteem (Model 2); and self-esteem and death anxiety were negatively correlated ( $\beta=-0.54, p<0.01$; Model 3$)$. Next, hierarchical regression analysis was conducted to test the final steps of the mediation procedure. However, when selfesteem was added to the regression analysis, the significance of the relationship between presence of meaning and death anxiety declined $(\beta=-0.17, p<0.01)$ and that between search for meaning and death anxiety became insignificant $(\beta=-0.07, p=0.22)$. According to Baron and Kenny [38], these results indicate partial mediation between presence of meaning and death anxiety and complete mediation between search for meaning and death anxiety (Table 2).

Next, path analysis was carried out in Amos 17.0. A partially mediated model containing mediators (self-esteem) and direct paths from search for meaning and presence of meaning to death anxiety was tested. The direct path from search for meaning and death anxiety was insignificant $(\beta=-0.07, p=0.22)$ and thus deleted. The final model is presented in Fig. 1. This model exhibited a good fit with the data $\left[\mathrm{X}^{2}(d f=1)=1.53\right.$, RMSEA = 0.02 , SRMR $=0.046, \mathrm{CFI}=0.99]$, implying that self-esteem partially mediated the effect of presence of meaning on death anxiety and completely mediated the effect of search for meaning on death anxiety. Then, the mediating effects were tested for significance using the bootstrap estimation procedure in Amos 17.0 (a bootstrap sample of 1500 was specified). Table 3 shows the direct and indirect effects and their associated 95\% confidence intervals. All confidence intervals did not include 0 , indicating that all paths in the mediated model were significant. Taken together, these results reveal the mediating role of self-esteem in the relationship between meaning in life and death anxiety, supporting the hypothesis of the current study. According to literature requirements [40], no multicollinearity was apparent between independent variables; tolerance ranged between 0.62 and 0.72 , and variance inflation factors ranged between 1.46 and 1.63 .

\section{Discussion}

This study aimed to identify a mediating role in the relationship between meaning in life and death anxiety in Chinese older adults. China has faced accelerated aging since the 1990s. The number of older adults (aged $\geq 65$ ) increased from 62.99 million in 1990 to 140 million in 2015 (i.e., from $5.6 \%$ of the total population to $10.1 \%$ ), indicating that China is now an aging society. There is no life without death; however, human beings possess the cognitive ability to be aware of their own mortality and to feel anxious regarding what may come afterwards. As individuals grow older, the specter of death begins to hover and prevents people from being completely free from death anxiety [22]. Furthermore, China is an atheistic country. According to national surveys conducted in the early twenty-first century, approximately $73.56 \%$ of China's population (i.e., more than a billion people)

Table 2 Multiple regression analysis

\begin{tabular}{|c|c|c|c|c|c|c|c|}
\hline \multirow[t]{2}{*}{ Model } & \multirow[t]{2}{*}{ Dependent } & \multirow[t]{2}{*}{ Predictors } & \multicolumn{2}{|c|}{ Model summary } & \multicolumn{3}{|c|}{ Coefficients } \\
\hline & & & $\bar{F}$ & $R^{2}$ & $\bar{B}$ & SE & $\beta$ \\
\hline \multirow[t]{2}{*}{1} & Death anxiety & Presence of meaning & $34.54^{* *}$ & 0.20 & -0.29 & 0.05 & $-0.37^{* *}$ \\
\hline & & Search for meaning & & & -0.11 & 0.06 & $-0.13^{* *}$ \\
\hline \multirow[t]{2}{*}{2} & Self-esteem & Presence of meaning & $54.87^{* *}$ & 0.28 & 0.36 & 0.04 & $0.46^{* *}$ \\
\hline & & Search for meaning & & & 0.12 & 0.05 & $0.13^{* *}$ \\
\hline 3 & Death anxiety & Self-esteem & $117.73^{* *}$ & 0.30 & -0.55 & 0.05 & $-0.54^{* *}$ \\
\hline \multirow[t]{3}{*}{4} & Death anxiety & Presence of meaning & $45.70^{* *}$ & 0.33 & -0.14 & 0.05 & $-0.17^{* *}$ \\
\hline & & Search for meaning & & & -0.07 & 0.05 & -0.07 \\
\hline & & Self-esteem & & & -0.43 & 0.06 & $-0.43^{* *}$ \\
\hline
\end{tabular}




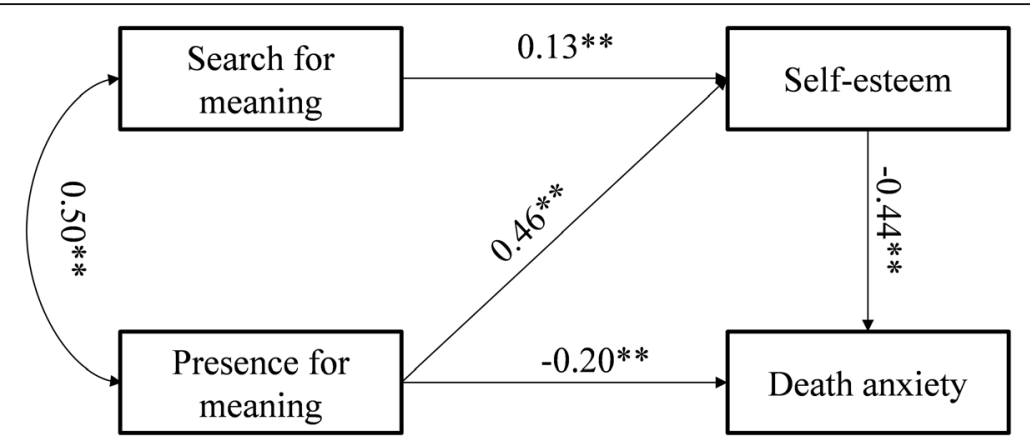

Fig. 1 The final mediating effect model of self-esteem between meaning in life and death anxiety. Note: Search for meaning and Presence for meaning are two dimensions of meaning in life. All the coefficients are standardized, ${ }^{* *} p<0.01$

are irreligious [41, 42]; the vast majority of Chinese participate in cosmological religion and exhibit no definitive religious beliefs, although religion may greatly relieve death anxiety [43]. Considering that China is home to one-fifth of the world's older adults, many of whom possess no religious beliefs, it is highly important to study influential factors on death anxiety.

This study reveals that meaning in life is negatively correlated with death anxiety among older adults; higher scores on assessment dimensions regarding meaning in life reflected lower death anxiety. This finding is consistent with many prior studies. For instance, Ardelt also found meaning in life to be negatively associated with death anxiety among older adults [44]. Moore and colleagues determined that older adults with higher scores on meaning in life could face death optimistically even when suffering [45]. Older adults with higher meaning in life appear to clearly understand the meaning of life, interpret the essence of life based on their own values, and recognize the goals and values of their survival and life; therefore, they could look objectively at death, calmly accept death-related events, and experience less death anxiety [45]. As mentioned above, MMT suggests that the best way to reduce death anxiety is to facilitate acceptance of death and to seek the meaning of life. This theory suggests that a better understanding of the meaning and goals of life can reduce or eliminate anxiety and negative emotions related to death or near-death [24]. Results of this study demonstrate a negative correlation between meaning in life and death anxiety, which is consistent with MMT.

Our findings also revealed the mediating role of selfesteem between meaning in life and death anxiety. The two dimensions of meaning in life-presence of meaning and search for meaning-can each predict death anxiety through self-esteem, and self-esteem completely mediates the effect of search for meaning on death anxiety. These findings coincide with existing views. Scholars have suggested that meaning in life serves four important functions for humans, providing (1) life goals; (2) values and standards for the self-assessment of behavior; (3) a sense of control over life events; and (4) feelings of self-worth [46-49]. Self-esteem represents an overall assessment of the self and is therefore closely associated with these functions of meaning in life. People's selfesteem can be enhanced through a sense of life value and the continuous pursuit of goals in life [34]. TMT, in seeking to minimize fear of death, assumes that cultural systems can serve as buffers against death anxiety. TMT holds that self-esteem is a feeling of "I am one valuable part of this meaningful world" [26, 50]. MMT, with the purpose of maximizing death acceptance and self-actualization,

Table 3 Direct and indirect effects of meaning in life on death anxiety

\begin{tabular}{|c|c|c|c|}
\hline Model pathways & Estimated effect & Lower bonds & Up bonds \\
\hline \multicolumn{4}{|l|}{ Direct effect } \\
\hline Search for meaning $\rightarrow$ Self-esteem & .13 & .06 & .29 \\
\hline Presence for meaning $\rightarrow$ Self-esteem & .46 & .27 & .66 \\
\hline Presence for meaning $\rightarrow$ Death anxiety & -.20 & -.34 & -.11 \\
\hline Self-esteem $\rightarrow$ Death anxiety & -.44 & -.57 & -.28 \\
\hline \multicolumn{4}{|l|}{ Indirect effect } \\
\hline Search for meaning $\rightarrow$ Self-esteem $\rightarrow$ Death anxiety & -.06 & -.13 & -.03 \\
\hline Presence for meaning $\rightarrow$ Self-esteem $\rightarrow$ Death anxiety & -.20 & -.35 & -.10 \\
\hline
\end{tabular}


suggests that an individual can resist fear and anxiety surrounding death when he/she realizes the meaning of life and his/her personal worth [51]. Humans need selfesteem because the self-regulatory mechanism associated with it provides an elastic space that helps individuals alleviate anxiety [52]. According to these theories, when individuals ponder death-related issues, they contemplate their own worth ("Everyone eventually dies, so why are we alive, and what is the meaning of life?") and become anxious about conflicting personal values. In this case, death anxiety can be relieved only if an individual realizes the values and meaning of life and feels that he/she is a valuable individual and is "one valuable part of this meaningful world," which exemplifies selfesteem. That is, the experience and search for meaning in life by older adults should foster the realization that their lives are valuable and meaningful. This experience (i.e., self-esteem) further reduces anxiety caused by the reality that death is inevitable.

The findings of this study provide a more positive and hopeful perspective on death anxiety and carry important implications for practitioners working with people struggling with death anxiety. People may benefit from identifying or creating value and meaning in later stages of life, as evidenced by the current study; this notion coincides with the promotion of positive psychology and gradual reductions in death anxiety [53]. Thibault et al. suggested that practitioners should help patients seek or create value in later stages of life, however long that may be [54]. For example, people diagnosed with terminal cancer do not need to suffer from death anxiety and lose their remaining days waiting for death. Every person must face the looming threat of death; however, individuals can always unleash their inner potential to become a valuable part of a meaningful world (thus increasing their self-esteem) by constructing and seeking meaning for living. Such steps can transform death anxiety into a source of inspiration for an authentic life.

The current study also provides clinical implications related to counseling older adults who feel close to death. For example, staff who work in psychological counseling can help older adults to consolidate and enhance meaning in life by pointing out important life purposes and values, which will enable clients to enhance their self-esteem and serve as a buffer against death anxiety. In line with supporters of positive psychology, meaning-oriented interventions aimed at finding intentionality and goals may help individuals effectively reinforce coping strategies $[55,56]$. Accordingly, psychological counselors could adopt interventions and counseling approaches to promote meaning in life and self-esteem to address death anxiety. Based on TMT, this type of clarity can be gained by assisting individuals in conforming to cultural and personal value standards and norms [23].
This study has some limitations. First, similar to related studies, a major limitation of this research is that findings relied on a cross-sectional sample of older adults; it was not a longitudinal study, which prevented the authors from establishing causal relationships regarding the concurrent effects of meaning in life and self-esteem on death anxiety. Future studies should test the presented mediating models using longitudinal approaches or a log linear method. Second, this study adopted a self-response method to measure death anxiety; responses may have been susceptible to social desirability effects (e.g., if respondents reported less death anxiety than they actually felt). Thus, more fully developed approaches can be used to replicate this method in subsequent studies and may reveal more interesting results. Third, we determined that self-esteem mediates the effect of meaning in life on death in older adults. Humans' reactions to death anxiety are dynamic and multifaceted $[4,57$, 58]; therefore, additional mediating factors may influence the relationship between meaning in life and death anxiety. Other active elements may thus serve protective functions against death anxiety, such as attribution styles and dispositional optimism, and should be considered in future studies. Last but not least, this study's theoretical and empirical findings may oppose those of other studies, such as results suggesting that the direct effect of death salience may enhance death anxiety by eliciting regret and thoughts about the meaninglessness of death $[31,59]$. This issue should be considered in future research.

\section{Conclusion}

Death anxiety is a common phenomenon when older adults acknowledge their own mortality [60]. This study intended to explore potential solutions to relieve death anxiety in this population; findings indicated that selfesteem has a mediating effect in the connection between meaning in life and death anxiety in the Chinese elderly. These results provide additional insight into the limited body of work exploring the role of overall self-assessment in the connection between life goals and values and psychological distress that older adults experience as they realize that their lives are becoming increasingly short. Helping older adults consolidate and improve meaning in life should enable them to enhance their self-esteem and further alleviate death anxiety.

\section{Abbreviations}

MMT: Meaning Management Theory; TMT: Terror Management Theory

\section{Acknowledgments \\ Not applicable.}

\section{Authors' contributions}

Conceived and designed the experiments: JXZ JXP DMM. Performed the experiments: PG HH YFC. Analyzed the data: JXZ JXP LLZ. Contributed reagents/materials/analysis tools: JXZ JXP DMM. Wrote the paper: JXZ JXP. All authors have read and approved the manuscript. 


\section{Funding}

This study was founded by the National Natural Science Foundation of China (No. 31900791), and the MOE (Ministry of Education in China) Project of Humanities and Social Sciences (No. 19YJC190020). The funders had no roles in the study design, data collection and analysis, decision to publish, or preparation of the manuscript.

\section{Availability of data and materials}

Data is stored at the author's university. The data is available from the corresponding authors on reasonable request.

\section{Ethics approval and consent to participate}

All participants were informed of the purpose and voluntary nature of the survey and were assured anonymity on all responses. Written informed consent was obtained from all the participants. This study was approved by the Committee on Human Experimentation of the Air Force Military Medical University.

\section{Consent for publication}

Not applicable.

\section{Competing interests}

The authors declare that they have no competing interests.

\section{Author details}

${ }^{1}$ Xi'an Research Institute of High-technology, Xi'an, China. ${ }^{2}$ College of Teachers, Chengdu University, Chengdu, China. ${ }^{3}$ Department of Military Medical Psychology, Air Force Military Medical University, Xi'an, China.

\section{Received: 30 January 2019 Accepted: 11 October 2019}

Published online: 12 November 2019

\section{References}

1. Wu AM, Tang CS, Kwok TC. Death anxiety among Chinese elderly people in Hong Kong. J Aging Health. 2002;14(1):42-56.

2. Fortner BV, Neimeyer RA. Death anxiety in older adults: a quantitative review. Death Stud. 1999;23(5):387-411.

3. Alkozei A, Smith R, Demers LA, Weber M, Berryhill SM, Killgore WD. Increases in emotional intelligence after an online training program are associated with better decision-making on the lowa gambling task. Psychol Rep. 2019; 122(3):853-879

4. Kesebir P. A quiet ego quiets death anxiety: humility as an existential anxiety buffer. J Pers Soc Psychol. 2014;106(4):610-23.

5. Malinauskaite I, Slapikas R, Courvoisier D, Mach F, Gencer B. The fear of dying and occurrence of posttraumatic stress symptoms after an acute coronary syndrome: a prospective observational study. J Health Psychol. 2017:22(2):208-17.

6. Vida C, M Gonzalez E, De la Fuente M. Increase of oxidation and inflammation in nervous and immune systems with aging and anxiety. Curr Pharm Des. 2014;20(29):4656-78.

7. Mykletun A, Bjerkeset O, Prince M, Dewey M, Stewart R. Levels of anxiety and depression as predictors of mortality: the HUNT study. Br J Psychiatry. 2009;195(2):118-25.

8. Schulz R, Drayer RA, Rollman BL. Depression as a risk factor for non-suicide mortality in the elderly. Biol Psychiatry. 2002;52(3):205-25

9. Peng J, Feng T, Zhang J, Zhao L, Zhang Y, Chang Y, et al. Measuring decision-making competence in Chinese adults. J Behav Decis Mak. 2019:32:266-79.

10. Barnett MD, Anderson EA, Marsden AD. Is death anxiety more closely linked with optimism or pessimism among older adults? Arch Gerontol Geriatr. 2018;77:169-73

11. Florian V, Mikulincer M. Symbolic immortality and the management of the terror of death: the moderating role of attachment style. J Pers Soc Psychol. 1998;74(3):725-34

12. Steger MF, Frazier P. Meaning in life: one link in the chain from religiousness to well-being. J Couns Psychol. 2005;52(4):574-82.

13. Steger MF, Kashdan TB, Sullivan BA, Lorentz D. Understanding the search for meaning in life: personality, cognitive style, and the dynamic between seeking and experiencing meaning. J Pers. 2008;76(2):199-228.

14. Steger MF, Oishi S, Kashdan TB. Meaning in life across the life span: levels and correlates of meaning in life from emerging adulthood to older adulthood. J Posit Psychol. 2009;4(1):43-52.
15. Steger MF. Making meaning in life. Psychol Inq. 2012;23(4):381-5.

16. Meier A, Edwards H. Purpose-in-life test: age and sex differences. J Clin Psychol. 1974;30(3):384-6.

17. Frenz AW, Carey MP, Jorgensen RS. Psychometric evaluation of Antonovsky's sense of coherence scale. Psychol Assess. 1993;5(2):145-53.

18. Oishi S, Diener E. Residents of poor nations have a greater sense of meaning in life than residents of wealthy nations. Psychol Sci. 2014; 25(2):422-30.

19. Routledge C, Juhl J. When death thoughts lead to death fears: mortality salience increases death anxiety for individuals who lack meaning in life. Cognit Emot. 2010;24(5):848-54.

20. Tang CS-K, Wu AM, Yan EC. Psychosocial correlates of death anxiety among Chinese college students. Death Stud. 2002;26(6):491-9.

21. Lyke J. Associations among aspects of meaning in life and death anxiety in young adults. Death Stud. 2013;37(5):471-82.

22. Wong PT. Meaning management theory and death acceptance. In: Existential and spiritual issues in death attitudes. Mahwa: Psychology Press; 2013. p. 91-114.

23. Greenberg J, Solomon S, Pyszczynski T. Terror management theory of selfesteem and cultural worldviews: empirical assessments and conceptual refinements. In: Advances in experimental social psychology, vol. 29. Orlando: Elsevier; 1997. p. 61-139.

24. Juhl J, Routledge C, Arndt J, Sedikides C, Wildschut T. Fighting the future with the past: nostalgia buffers existential threat. J Res Pers. 2010;44(3):309-14.

25. Davis SF, Bremer SA, Anderson BJ, Tramill JL. The interrelationships of ego strength, self-esteem, death anxiety, and gender in undergraduate college students. J Gen Psychol. 1983;108(1):55-9.

26. Abeyta AA, Juhl J, Routledge C. Exploring the effects of self-esteem and mortality salience on proximal and distally measured death anxiety: a further test of the dual process model of terror management. Motiv Emot. 2014;38(4):523-8.

27. Hiyoshi K, Becker C, Oishi N, Fukuyama H. A review of effects of death anxiety on the human brain. J Neurol Sci. 2017;381:257-68.

28. Rosenblatt A, Greenberg J, Solomon S, Pyszczynski T, Lyon D. Evidence for terror management theory: I. the effects of mortality salience on reactions to those who violate or uphold cultural values. J Pers Soc Psychol. 1989; 57(4):681-90.

29. Missler M, Stroebe M, Geurtsen L, Mastenbroek M, Chmoun S, Van Der Houwen K. Exploring death anxiety among elderly people: a literature review and empirical investigation. Omega-J Death Dying. 2012;64(4): 357-79.

30. Maxfield M, Pyszczynski T, Greenberg J, Bultmann MN. Age differences in the effects of mortality salience on the correspondence bias. Int J Aging Hum Dev. 2017:84(4):329-42.

31. Bergman YS, Bodner E, Haber Y. The connection between subjective nearness-to-death and depressive symptoms: the mediating role of meaning in life. Psychiatry Res. 2018;261:269-73.

32. Steger MF, Frazier P, Oishi S, Kaler M. The meaning in life questionnaire: assessing the presence of and search for meaning in life. J Couns Psychol. 2006:53(1):80-93.

33. Dezutter J, Waterman AS, Schwartz SJ, Luyckx K, Beyers W, Meca A, et al. Meaning in life in emerging adulthood: a person-oriented approach. J Pers. 2014;82(1):57-68.

34. Martela F, Steger MF. The three meanings of meaning in life: distinguishing coherence, purpose, and significance. J Posit Psychol. 2016:11(5):531-45.

35. Zhang H, Sang Z, Chan DK-S, Teng F, Liu M, Yu S, et al. Sources of meaning in life among Chinese university students. J Happiness Stud. 2016:17(4): 1473-92.

36. Cheung PC, Lau S. Self-esteem: its relationship to the family and school social environments among Chinese adolescents. Youth Soc. 1985;16(4): 438-56.

37. Templer DI. The construction and validation of a death anxiety scale. J Gen Psychol. 1970;82(2):165-77

38. Baron RM, Kenny DA. The moderator-mediator variable distinction in social psychological research: conceptual, strategic, and statistical considerations. J Pers Soc Psychol. 1986;51(6):1173-82.

39. Peng J, He Y, Deng J, Zheng L, Chang Y, Liu X. Emotional labor strategies and job burnout in preschool teachers: psychological capital as a mediator and moderator. Work. 2019;62:49-58.

40. O'brien RM. A caution regarding rules of thumb for variance inflation factors. Qual Quant. 2007:41(5):673-90. 
41. Wang $X$, Jang SJ. The relationship between religion and deviance in a largely irreligious country: findings from the 2010 China general socia survey. Deviant Behav. 2017;38(10):1120-40.

42. Yang Y, Huang S. Religious beliefs and environmental behaviors in China. Religions. 2018;9(3):72.

43. Harding SR, Flannelly KJ, Weaver AJ, Costa KG. The influence of religion on death anxiety and death acceptance. Ment Health, Religion Culture. 2005; 8(4):253-61.

44. Ardelt M. Effects of religion and purpose in life on elders' subjective wellbeing and attitudes toward death. J Relig Gerontol. 2003;14(4):55-77.

45. Moore SL, Metcalf B, Schow E. The quest for meaning in aging. Geriatr Nurs. 2006;27(5):293-9.

46. Bailey $T H$, Phillips $L J$. The influence of motivation and adaptation on students' subjective well-being, meaning in life and academic performance. Higher Educ Res Dev. 2016:35(2):201-16.

47. Das AK. Frankl and the realm of meaning. J Humanist Counsel. 1998;36(4): 199-211.

48. Peng J, Zhang J, Zhang Y, Gong P. Relative deprivation and job satisfaction in Army officers: a moderated mediation model. Work. 2019;62(1):49-58.

49. Peng J, Zhang J, Sun H, Zeng Z, Mai Y, Miao D. Mixed frames and risky decision-making. Psychol Rep. 2017;120(6):1037-57.

50. Juhl J, Routledge C. Putting the terror in terror management theory: evidence that the awareness of death does cause anxiety and undermine psychological well-being. Curr Dir Psychol Sci. 2016;25(2):99-103.

51. Gond JP, Cabantous L, Harding N, Learmonth M. What do we mean by performativity in organizational and management theory? The uses and abuses of performativity. Int J Manag Rev. 2016;18(4):440-63.

52. Wisman A, Heflick N, Goldenberg JL. The great escape: the role of selfesteem and self-related cognition in terror management. J Exp Soc Psychol. 2015;60:121-32

53. Donaldson SI, Dollwet M, Rao MA. Happiness, excellence, and optimal human functioning revisited: examining the peer-reviewed literature linked to positive psychology. J Posit Psychol. 2015;10(3):185-95.

54. Thibault JM, O'Brien JG, Turner LC. Indirect life-threatening behavior in elderly patients. J Elder Abuse Negl. 2000;11(2):21-32.

55. Sheldon KM, King L. Why positive psychology is necessary. Am Psychol. 2001;56(3):216-7.

56. Seligman MEP, Steen TA, Park N, Peterson C. Positive psychology Progress: empirical validation of interventions. Am Psychol. 2005:60(5):410-21.

57. Rahimah A, Khalil S, Cheng JMS, Tran MD, Panwar V. Understanding green purchase behavior through death anxiety and individual social responsibility: mastery as a moderator. J Consum Behav. 2018;17(5):477-90.

58. McKenzie EL, Brown PM, Mak AS, Chamberlain P. 'Old and ill': death anxiety and coping strategies influencing health professionals' well-being and dementia care. Aging Ment Health. 2017;21(6):634-41.

59. Tomer A, Eliason G. Toward a comprehensive model of death anxiety. Death Stud. 1996;20(4):343-65.

60. Depaola SJ, Griffin M, Young JR, Neimeyer RA. Death anxiety and attitudes towardthe elderly among older adults: the role of gender and ethnicity. Death Stud. 2003:27(4):335-54

\section{Publisher's Note}

Springer Nature remains neutral with regard to jurisdictional claims in published maps and institutional affiliations.

Ready to submit your research? Choose BMC and benefit from:

- fast, convenient online submission

- thorough peer review by experienced researchers in your field

- rapid publication on acceptance

- support for research data, including large and complex data types

- gold Open Access which fosters wider collaboration and increased citations

- maximum visibility for your research: over $100 \mathrm{M}$ website views per year

At $\mathrm{BMC}$, research is always in progress.

Learn more biomedcentral.com/submissions 